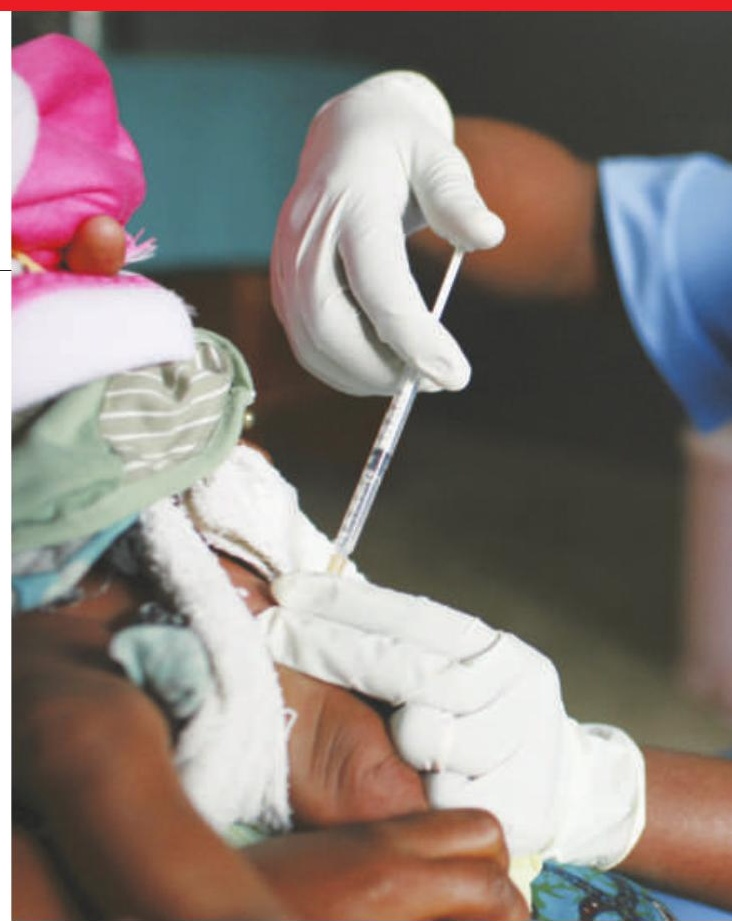

Malaria vaccine gets shot in the arm from tests

\section{Promising results pave the way for a vaccine candidate to undergo full-blown trials across Africa.}

A long-anticipated candidate vaccine for malaria may be more than $50 \%$ effective at preventing the disease in African children, say results published this week in The New England Journal of Medicine ${ }^{1,2}$. The work sets the scene for phase III clinical trials to start within the next few months.

The vaccine, called RTS,S, has been in development for more than two decades ${ }^{3}$, and earlier studies had suggested that it was effective at rates of little better than $30 \%$. Yet even modest protection against malaria is deemed a success because of the disease's deadly and endemic nature. But "there's something quite important in getting beyond 50\%", says Kevin Marsh, director of the KEMRI-Wellcome research programme in Kilifi, Kenya. "It really strengthens the argument that it will be possible to develop something like a complete vaccine."

Malaria experts are impressed with the latest findings, which were also presented on 8 December at a meeting of the American Society of Tropical Medicine and Hygiene in New Orleans, Louisiana. "Overall, these show good progress with RTS,S," says Adrian Hill, director of the Jenner Institute in Oxford, UK, who was not directly involved in the work.

The results are from phase II trials conducted at three sites in western Africa by the vaccine developer GlaxoSmithKline (GSK) and a wide-ranging team of clinical, academic and non-profit funding partners. The next step will be phase III trials, which scale up the numbers treated. These will be funded largely by the Bill \& Melinda Gates Foundation in Seattle, and will involve up to 16,000 children at 10 sites in 7 African countries (see map).

In work described in one of the new papers ${ }^{1}$, more than 800 children aged 5 to 17 months in Kenya and Tanzania received either the RTS,S vaccine or a rabies vaccine as a control. After an average follow-up of eight months, only 32 children in the RTS,S group had developed clinical malaria compared with 66 in the control group. That corresponds to roughly $53 \%$ efficacy.

The trial tested a newer vaccine formulation that uses an adjuvant called AS01 to help stimulate an immune response. AS01 seems to trigger much stronger antibody responses in the body than the previous adjuvant used, but this still doesn't translate into massive gains in protection against clinical malaria. Marsh, a co-author of the work, calls this disparity puzzling and frustrating, as complicated clinical trials such as these are the only way to get a good idea of efficacy. Part of the problem, Marsh says, is that "no one really knows how RTS,S works".

The other study, conducted in Bagamoyo, Tanzania, was smaller and was mainly concerned with the feasibility and safety of administering RTS,S with other vaccines. A group of 340 infants was given either RTS,S or the hepatitis $B$ vaccine, together with routine vaccines for diphtheria, tetanus, pertussis and

\title{
France cracks down on Iranian scientists
}

Europe's largest basic-research agency, the CNRS in France, is now vetting not only non-European Union (EU) researchers working on sensitive topics, but also all scientists from Iran regardless of what they work on. Researchers allege that the move exacerbates an already difficult situation in which visa applications are denied based on nationality.

A 12 November memo, relayed by the CNRS's security office from the state national security and industrial espionage services, requires that all projects with Iran go through formal security screening, to identify ones potentially meriting further scrutiny. It translates $\mathrm{UN}$ sanctions that call for member states not to provide
Iran with technical assistance or training that might be used for the proliferation of weapons of mass destruction, says Joseph Illand, who heads the CNRS security office.

It's the first case Illand can recall of such an explicit country-specific instruction at the CNRS - although similar, if unwritten, restrictions have in practice long been in effect for Iran and other countries considered as security risks. Given the threat of proliferation, such extra scrutiny is normal, he says.

The rules expand on those introduced in January 2005, which require extra scrutiny for visits from non-EU scientists whose work relates to an undisclosed list of 'sensitive' laboratories or topics. In such cases, the heads of host laboratories must give details of proposed visits, and their opinion of the visitor, to security authorities. For lesssensitive laboratories, lab heads need only declare foreign visitors monthly, whereas no-risk labs must simply maintain an internal register that can be consulted by authorities if needed.

In recent years, Iranian researchers have struggled for academic equality and scientific access. In July, for instance, the Netherlands banned Iranians from accessing nuclear laboratories or courses, and the United States has subjected Iranian visa requests to lengthy interagency reviews in the wake of the terrorist attacks of 11 September 2001. Britain last year also introduced tough vetting of non-EU science students.

The fact that France is cracking down on Iranian researchers 


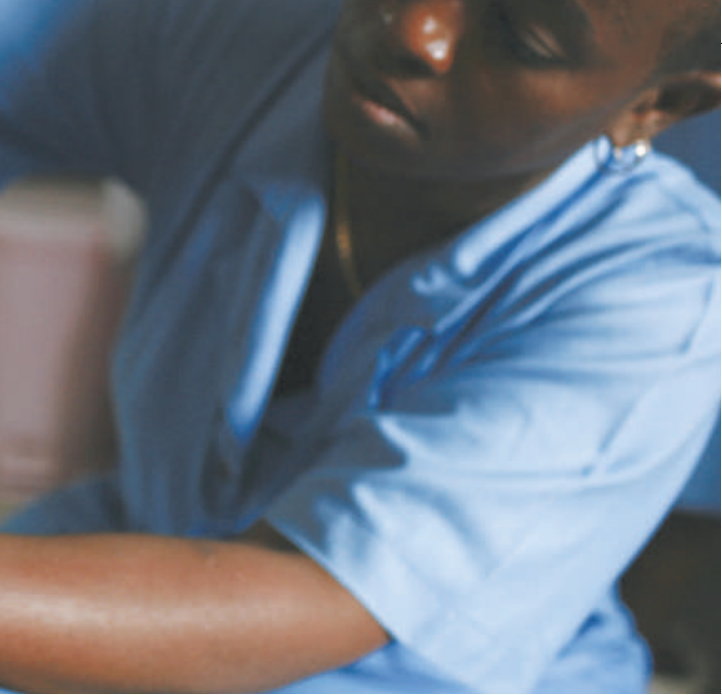

Two African studies raise hopes that an effective malaria vaccine may be in sight.

Haemophilus influenza type b, offered under a World Health Organization immunization programme. "Using the vehicle of distribution that already exists would make it easy to rapidly scale up the accessibility of a potentially good malaria vaccine to many children," says first author Salim Abdulla of the Ifakara Health Institute in Bagamoyo.

RTS,S, used in this study with the older adjuvant AS02, did not interfere with the other vaccines; nor did these other vaccines interfere with the ability of RTS,S to elicit an immune response. Although the study was not designed to test for effectiveness, the results did suggest that malaria infection rates were lower in vaccinated children.

Questions remain about how long protection might last. A study ${ }^{4}$ in Mozambique published in 2004 found that the RTS,S vaccine was more than $30 \%$ effective in children aged 1 to 4 years. Long-term follow-up in one cohort showed that that efficacy was maintained, but unpublished data on a second cohort showed a dramatic fall in the 18 months following vaccination.

Joe Cohen, a vice-president at GSK and a key developer of RTS,S, says these findings have been submitted for publication. According to other sources, several factors could explain the fall-off, including a reportedly high transmission rate at the site of cohort two. But Cohen is still upbeat about RTS,S based on many other completed trials. "Right now we feel extremely confident with the overall data," he says.

New trials, and continued follow-up on current studies, should help pin down exactly for how long efficacy might be maintained. The phase III trials will be conducted in areas of varying transmission rates, which may affect the observed efficacy. And in general, sites with ongoing malaria trials tend to have lower transmission rates than other parts of Africa,

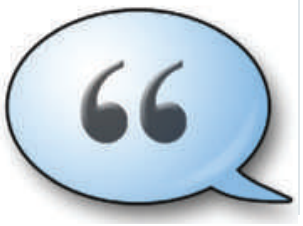

HAVE YOUR SAY

Comment on any of our news stories, online. www.nature.com/news simply because countermeasures such as bednets are more widely available at these developed research sites.

Some researchers, including Hill, want greater attention paid to developing a more effective second-generation vaccine. This might combine RTS,S with other promising candidates, which he says GSK has been reluc-

tant to agree to. Cohen says GSK would be willing to try combinations with other vaccine candidates of proven efficacy, but so far there aren't any.

Still, the new results have edged RTS,S closer to its goal. "The vaccine is clearly having an effect, and we're all waiting expectantly to see how it stands up in the large phase III studies," says Stephen Hoffman, who was involved developing RTS,S precursors but now works on another malaria vaccine candidate at his company Sanaria in Rockville, Maryland. "It's an exciting time."

Brendan Maher

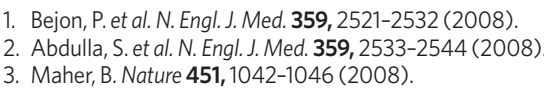

. Maher B Nature 451, 1042-1046 (2008).

4. Alonso, P. L. et al. Lancet 364, 1411-1420 (2004) doesn't surprise Carthage Smith, deputy executive director for the International Council for Science in Paris, and a member of its human-rights committee. "There are legitimate concerns in the international community at present about the risk of technology transfer to Iran and other specific countries," he says. "We can't ignore that."

But he worries about how the rules might be implemented. "Any vetting must be separate from country lists, with each individual case being judged on its merits," he says. Otherwise, overzealous bureaucrats could turn country listings into effective blacklists. Formalizing extra vetting for Iranian researchers may have secondary effects, admits Illand, in that French hosts might show less interest in collaborating with
Iranians to avoid administrative hassle, or government bureaucrats may be tempted to play safe and turn down visa applications. Many within the CNRS and the French administration, he says, support greater collaboration with Iran as a form of scientific diplomacy.

Overall statistics are not available, but Nature has gathered complaints from more than a dozen Iranian scientists who allege that French authorities recently either refused their requests for visas or simply never responded.

Take Ali Tahzibi, a mathematician and Iranian national at the Federal University of São Carlos in Brazil. In July he applied for a visa to work for a year, starting in October, with
Christian Bonatti at the CNRS's Institute of Mathematics, part of the University of Bourgogne in Dijon. Tahzibi took a year's sabbatical, bought plane tickets for himself and his family, rented an and arranged schooling stop looking at for his son. The visa researchers' passports, and start looking at their work." never materialized. "To wait up until just hours before your flight in the hope of getting a visa without obtaining any response was torture for a family with a little

\section{child," says Tahzibi.}

Visa-seeking researchers share common stories of being passed back and forth within the French bureaucracy. "It's a typical administrative vicious circle," says

Pierre Sens, a researcher at the Paris
Industrial Physics and Chemistry Higher Educational Institution, who tried to intervene on behalf of a former postdoc and Iranian national. The office of Valérie Pécresse, the minister of research and higher education, declined to comment on the allegations or their impact on collaboration, instead referring Nature to the ministry of immigration.

The cases and the CNRS policy are "absolutely astonishing, if not scandalous on the part of a country such as France, which sees itself as the cradle of human rights", says Thierry Dauxois, a CNRS physicist at the Ecole Normale Supérieure in Lyon. "They need to stop looking at researchers' passports, and start looking at their work."

Declan Butler

See also Editorial, page 675. 